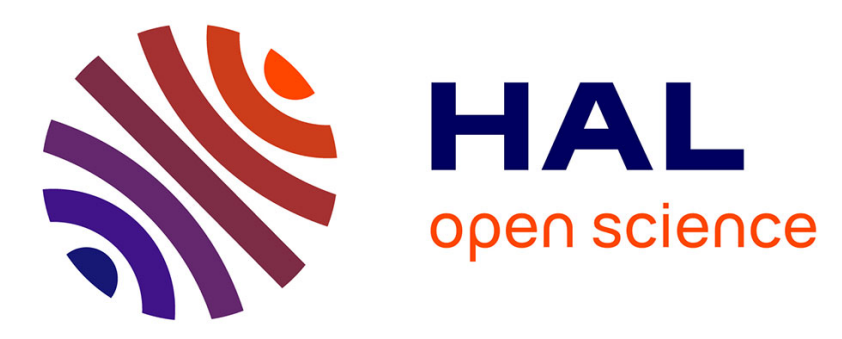

\title{
Effect of retentive markers on the dynamics of settlement: The case of arthropod silk
}

\author{
Aina Astudillo Fernandez, Anne-Catherine Mailleux, Fabrice Saffre, Bertrand
}

Krafft, Jean Louis Deneubourg

\section{To cite this version:}

Aina Astudillo Fernandez, Anne-Catherine Mailleux, Fabrice Saffre, Bertrand Krafft, Jean Louis Deneubourg. Effect of retentive markers on the dynamics of settlement: The case of arthropod silk. Journal of Theoretical Biology, 2010, 265 (3), pp.411. 10.1016/j.jtbi.2010.05.014 . hal-00608421

\section{HAL Id: hal-00608421 \\ https://hal.science/hal-00608421}

Submitted on 13 Jul 2011

HAL is a multi-disciplinary open access archive for the deposit and dissemination of scientific research documents, whether they are published or not. The documents may come from teaching and research institutions in France or abroad, or from public or private research centers.
L'archive ouverte pluridisciplinaire HAL, est destinée au dépôt et à la diffusion de documents scientifiques de niveau recherche, publiés ou non, émanant des établissements d'enseignement et de recherche français ou étrangers, des laboratoires publics ou privés. 


\section{Author's Accepted Manuscript}

Effect of retentive markers on the dynamics of settlement: The case of arthropod silk

Aina Astudillo Fernandez, Anne-Catherine Mailleux, Fabrice Saffre, Bertrand Krafft, Jean Louis Deneubourg

PII:

S0022-5193(10)00243-2

DOI: doi:10.1016/j.jtbi.2010.05.014

Reference: YJTBI 5993

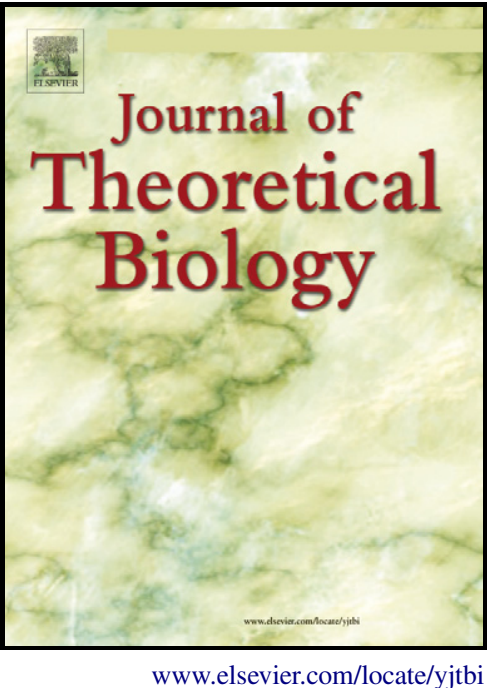

To appear in: $\quad$ Journal of Theoretical Biology

Received date: 23 December 2009

Revised date: 29 March 2010

Accepted date: 10 May 2010

Cite this article as: Aina Astudillo Fernandez, Anne-Catherine Mailleux, Fabrice Saffre, Bertrand Krafft and Jean Louis Deneubourg, Effect of retentive markers on the dynamics of settlement: The case of arthropod silk, Journal of Theoretical Biology, doi:10.1016/j.jtbi.2010.05.014

This is a PDF file of an unedited manuscript that has been accepted for publication. As a service to our customers we are providing this early version of the manuscript. The manuscript will undergo copyediting, typesetting, and review of the resulting galley proof before it is published in its final citable form. Please note that during the production process errors may be discovered which could affect the content, and all legal disclaimers that apply to the journal pertain. 


\title{
Effect of Retentive Markers on the Dynamics of Settlement: The Case of Arthropod Silk
}

\author{
Aina Astudillo Fernandez ${ }^{1 \mathrm{a}, \mathrm{b}}$, Anne-Catherine Mailleux ${ }^{\mathrm{b}}$, Fabrice Saffre ${ }^{\mathrm{a}}$, \\ Bertrand Krafft ${ }^{\mathrm{c}}$, Jean Louis Deneubourg ${ }^{\mathrm{a}}$ \\ ${ }^{a}$ Université libre de Bruxelles. CP 231. Bvd. du triomphe, 1050 Brussels, Belgium \\ ${ }^{b}$ Université catholique de Louvain. Pl. croix du Sud, 5, 1348, Louvain-la-Neuve, Belgium \\ ${ }^{c}$ Khalifa University of Science, Technology 85 Research. P.O.Box 127788, Abu Dhabi, \\ United Arab Emirates \\ ${ }_{472}^{4}$ rue du Bas de la Côte, 54710 Ludres, France
}

\begin{abstract}
During a settlement decision, the presence of conspecifics is crucial to species subject to Allee effects, for which the number of founders affects the subsequent growth of the colony. Marking the area (physically or chemically) conveys information about the number of conspecifics present in a new patch. Here, we study how the individual affinity for the marker affects the dynamics of a foundation process. A generic population model is presented, in which marking and affinity for the marker are at stake. Our results show that population size thresholds can appear, below which settlement is not possible. This model is then used to study the dynamics of migration and aggregation in a set of interconnected populations. We show that affinity for the marker can induce asymmetries in the population distribution. Anelosimus eximius is a social spider subject to Allee effects, for which silk
\end{abstract}

\footnotetext{
${ }^{1}$ Corresponding author: Astudillo Fernndez, A. (aastudil@ulb.ac.be - Tel:+3226505119 - Fax: +3226505987)
} 
potentially acts as a marker. We test our predictions with field experiments involving two populations of A.eximius in a Y-shaped setup. The agreement between our experimental and theoretical results strongly supports the validity of the model. This allows us to use the model to estimate a realistic set of parameters of biological significance to this social spider.

Keywords:

Population dynamics, Colonisation, Agregation, Anelosimus eximius, social spiders

\section{Introduction}

A key stage of population dynamics is the settlement of individuals in new environments. Settlement results from complex decision-making pro4 cesses regarding habitat selection. Consequently, its dynamics can greatly 5 vary depending on the different habitat selection strategies (Mihoub et al., 6 2009). Among the biotic factors which play a role in habitat selection are the 7 conspecifics. In many species, specially in group-living species, the presence 8 of conspecifics increases the probability of reaching a new patch (conspecific 9 attraction) or the probability of staying in a new patch (conspecific retention). Either way, the probability to settle in a patch increases with the 
throughout the animal kingdom (Mueller et al., 1997; Stamps, 1988). The most frequently mentioned benefits of settling near conspecifics include reduced search and settlement costs (Fletcher, 2006), the use of conspecifics as indicators of habitat quality (Doligez et al., 2003), and the fitness increase associated with Allee effects (Courchamp et al., 2008). While these ultimate causes have received great attention, relatively little research has focused on the mechanisms used to evaluate the presence and/or the number of conspecifics.

The mechanisms used to assess the number of conspecifics in a given patch depend to a great extent on the type of information available to the animal. When the sensory system does not allow access to global information (e.g. Long distance view of big mammals, auditory information for birds (see references in Forbes and Kaiser, 1994)), the evaluation of the number of conspecifics has to be based on local information. This is usually the case for arthropods. Some use indirect cues that are representative of the number of conspecifics. These cues are the result of environment modification or marker production (chemical or physical) by the conspecifics in a density-dependent manner (Depickère et al., 2004; Rivault et al., 1998).

To our knowledge, population models of conspecific attraction (Mihoub et al., 2009; Ray and Gilpin, 1991, Smith and Peacock, 1990) or retention (Jeanson and Deneubourg, 2007) have always assumed direct attraction between conspecifics. Therefore, the consequences of conspecific attraction when it is mediated by a marker remain unexplored. Yet, one can expect the resulting population dynamics to be different, since the marker accumulates in the patch, which potentially causes delays and reinforces feedback loops. Here, 
we study the effects of this habitat selection strategy on the dynamics of settlement.

We focus on the case of Anelosimus eximius, a social spider found in South America. The spiders of this species live in large colonies ranging from a few hundred to a few thousand individuals (Avilés and Trufiño, 1998). The benefits they obtain from living in groups are the result of cooperation in activities such as prey catching (Pasquet and Krafft, 1992), brood care (Avilés, 1986) and web construction (Christenson, 1984). Not surprisingly, they are submitted to multiple Allee effects: their survival and fecundity rates increase with colony size (Avilés and Trufiño, 1998) up to a certain extent. Although colonies are rather stable and may persist for several years in one site (Vollrath 1986), there are conditions that trigger dispersal of some individuals that then create new colonies. New foundations only take place at relatively large sizes of the mother colony (Avilés and Trufiño 1998), possibly when drought provokes a food shortage (Venticinque et al. 1993). Other causes of dispersal may be linked to sudden changes in the environment (a fallen tree, for instance) that might degrade the local conditions or the web. Departure may also be totally accidental (passive transport by animals or humans). In any case, when new colonies need to be founded, it is crucial for individuals to settle in a group, and there is experimental evidence of a group size threshold below which they are not likely to settle (Leborgne et al., 1994).

One way to ensure that there are enough settlers to guarantee the fitness of the colony is to disperse in a group. Anelosimus eximus exhibits various patterns of dispersal: swarming or budding (Vollrath, 1982) are the 
most common (Leborgne et al., 1994). Spiders may also leave the colony individually, however it has been shown that dragline attachment acts as a recruitment process (Jeanson et al., 2004a; Saffre et al.,1999), which makes it likely that isolated individuals end up aggregated with other spiders. Indeed, a group of spiders scattered in a bush tends to aggregate (Leborgne et al.,1994). Although these strategies increase the potential number of founders on arrival, they offer no information about the actual number of founders. Therefore, one could expect that spiders use additional mechanisms to assess group size in order to make an informed decision regarding settlement.

Our hypothesis is that silk, or some chemical component in it, acts as information about the number of settlers in a patch (Giraldeau,1997; Wagner and Danchin, 2003). The probability of settling in a given site would therefore increase with the amount of silk on that site. Bernard and Krafft (2002) used a T-maze to show that in Anelosimus eximius, spiders are attracted to conspecific silk. Furthermore, they showed that silk has a strong retention effect: spiders spent significantly more time on the branch containing silk. Affinity for silk has also been put forward in many other spider species (Krafft, 1970; Leborgne and Pasquet, 1987; Schuck-Paim and Jimenez Alonso, 2001).

We present a general model for the growth of a set of interconnected populations, where every individual produces and is retained by a marker (in this case, silk). First, we explore the results of the model for a single population. We show that affinity for silk can give rise to thresholds in the number of founders, below which the population does not settle. Then, we study the general case of $n$ populations, and demonstrate that a heterogeneous distri- 
bution of the population on equal sites can be stable due to the retentive effect of silk. Our model is validated by comparing theoretical predictions on the particular case of two interconnected populations with field experiments carried out in French Guiana on Anelosimus eximius. Finally, the importance of retentive markers is put forward with a comparison between our results and those of models in which retention is caused by the individuals directly.

\section{General population model}

The general theoretical setup consists of a system of $n$ interconnected populations. We define two variables: $N_{i}$ is the number of individuals on the $i^{\text {th }}$ patch and $S_{i}$ the quantity of silk accumulated on that patch. The model is based on the following assumptions: (1) The individual tendency to settle in a patch $i$ increases with the amount of silk $S_{i}$ accumulated in that patch. To model this, we define the probability to leave the patch as a decreasing function of the quantity of silk. The function $f\left(S_{i}\right)=\beta /\left(1+\left(S_{i} / \alpha\right)^{\epsilon}\right)$ can take several shapes, among which a threshold-type S-shape. Other typically used functions (Sumpter and Pratt, 2009) such as the sigmoid function give the same results. The maximal tendency to leave $\beta$ is halved for the quantity of silk $\alpha$, than can be seen as a "silk threshold". The shape of the function is determined by $\epsilon$. Biologically, $\epsilon$ can be understood as the sensitivity of the response (tendency to leave) to changes in the amount of silk, for quantities of silk approaching $\alpha$ (see Fig.1 for a graphical representation of $f\left(S_{i}\right)$ ). For very high values of $\epsilon$, the sensitivity of the response is so high that the departure rate switches sharply from the maximum to zero when the quantity of silk equals $\alpha ;(2)$ When individuals leave a patch, they have a probability 
$P_{e}$ of exiting the system, or a probability $1-P_{e}$ of spreading into the other patches. The probabilities of moving into any of the other patches are equal $1 /(n-1)$; (3) The time-scale we focus on (a couple of days) is short enough to discount births and deaths, as it takes approximately a month after oviposition for spiderlings to emerge (Avilés, 1986); (4) Silk is produced by every individual at a constant rate $\gamma ;(5)$ Silk degrades over time at a rate of $\theta S$. The system of Eq. 1 describes the population dynamics of the $i$ th patch:

$$
\begin{aligned}
& d N_{i} / d t=-N_{i} f\left(S_{i}\right)+(1-P e) /(n-1) \sum_{j \neq i} N_{j} f\left(S_{j}\right) \\
& d S_{i} / d t=\gamma N_{i}-\theta S_{i}
\end{aligned}
$$

\section{Dynamics of one population}

Before exploring the dynamics of the system, let us first consider the case of one population $(n=1)$. We assume that individuals have arrived using collective migration, thus there is a group of potential founders $N_{0}$ in a new patch. Individuals can settle or leave. When individuals leave, they exit the system and do not return. This particular case allows us to understand the dynamics of foundation when a group of founders arrives in a new patch, or more precisely, the effect of departure on this foundation process.

At this stage, it is convenient to scale the system of equations, that is to express it in non-dimensional terms (Eq. 2). Although this change of variables and parameters does not have a direct biological meaning, it reveals the links between parameters, and synthesises the information concerning their 
respective effects. Mathematically, it simplifies the analytical resolutions by reducing the number of parameters substantially.

We redefine the variables as follows. The number of individuals $N$ is replaced by the ratio between the number of individuals and the initial population size $X=N / N_{0}$. The quantity of silk $S$ is substituted by a new variable $Z=\beta S / \gamma N_{0}$ that is directly proportional to the quantity of silk. We also define two new parameters $a$ and $b$, that are directly proportional to $\alpha$ (threshold quantity of silk) and $\theta$ (degradation coefficient of silk) respectively. Finally, we define a new time $(\tau=\beta t)$. The results obtained with these scaled variables and parameters can easily be converted back into the biologically meaningful variables (See Table 1 for a summary of all variables and parameters).

$$
\begin{aligned}
& d X / d \tau=-X /\left(1+(Z / a)^{\epsilon}\right) \\
& d Z / d \tau=\quad X-b Z
\end{aligned}
$$

This system has only one stable steady state $(X=0, Z=0)$. However, the behaviour of the system is qualitatively different for $\epsilon \leq 1$ and $\epsilon>1$. For analytical clarity, we will develop only the case of $\epsilon=1$ and $\epsilon=2$ as examples of the two subsets. Numerical resolutions show consistency in the results for other values of $\epsilon$ in both subsets.

For $\epsilon=1$, the behaviour of the system is intuitive: regardless of the parameter set, population decreases until it becomes extinct. What varies with the parameters is the amount of time it takes. The slowest case possible is when $b=0$ (silk degradation rate $\theta$ is negligible). For non-zero values of 
$b$, the decrease of the population occurs more quickly (Fig. 2A,B).

For $\epsilon=2$ (or in fact for values of $\epsilon>1$ ), the non-linearity of the system makes its behaviour less intuitive. The system presents a particular behaviour if $b=0$. For some values of $a$, there is an asymptotic steady state $X_{A}>0$ (Fig. 2C). By "asymptotic steady state of a variable", we mean the value towards which the variable tends asymptotically, as time tends to infinity. It is not a steady state sensu stricto, because the other variable $(Z)$ continues to increase. Nevertheless it is the value of $X$ towards which the system converges. In biological terms, it means that eventually, the quantity of silk is such that the departure rate tends to zero and the population size tends asymptotically to a given fraction $X_{A}$ of the initial population (Eq. 3).

For details on the calculations, see Appendix A.

$$
X_{A}=X_{0}-a \pi / 2
$$

$$
X_{A}>0 \text { if } 0<a<2 / \pi \text { or } N_{0}>\alpha \beta \pi / 2 \gamma
$$

Our model can be used to determine the necessary conditions for a successful establishment. The parameter space in which the population stabilises at a fraction $X_{A}$ of the initial population can be interpreted biologically. First of all, $\epsilon>1$ means that the response of the spiders to the presence of silk has to be S-shaped. Secondly, $N_{0}>\alpha \beta \pi / 2 \gamma$ means that the initial population has to exceed a critical size, for the colony to be viable. Note that the larger the silk threshold $(\alpha)$ and the maximal departure rate $\beta$, the larger the population has to be in order to settle successfully. Logically, if silk production $(\gamma)$ is very intense, the population threshold is lowered.

This asymptotic steady state is a particularity of the case where degra- 
dation is negligible, however for $b \neq 0, X$ is also attracted to asymptotical steady state $X_{A}$, although not indefinitely (Fig. 2C). Nevertheless, if the population is maintained near the asymptotic steady state for long enough, reproduction can compensate for the departure rate of individuals until there is enough silk for the establishment to be successful.

\section{Flow between $n$ interconnected populations}

In this section, we focus on the flow between populations. Hence we will temporarily consider the probability of exiting the system $\left(P_{e}\right)$ to be nil. The combined effects of flow and departure $\left(P_{e}\right)$ are discussed in the next section.

The general form of the model for $n$ interconnected populations is given by Eq. 4 (in its scaled form).

$$
\begin{aligned}
& d X_{i} / d \tau=-X_{i} /\left(1+\left(Z_{i} / a\right)^{\epsilon}\right)+1 /(n-1) \sum_{j \neq i)} X_{j} /\left(1+\left(Z_{j} / a\right)^{\epsilon}\right) \\
& d Z_{i} / d \tau=X_{i}-b Z_{i}
\end{aligned}
$$

As for the isolated population, the dynamics vary depending on $\epsilon$. If $\epsilon \leq 1$ there is only one stable steady state $X_{1}=X_{2} \ldots=X_{n}$, which means that regardless of the initial conditions, the flow tends to equalise the size of the populations and they eventually reach the same size. If $\epsilon>1$, however, the system may exhibit an asymmetric stable steady state with one population greater than all the others $X_{1}>X_{2}=X_{3} \ldots=X_{n}$. Equation 5 gives the sizes of the populations at the asymmetric steady state when $\epsilon=2$.

$$
\begin{aligned}
& X_{1}=\left(1+\sqrt{1-4(n-1)(a b)^{2}}\right) / 2 \\
& X_{j}=\left(1-X_{1}\right) /(n-1) \quad \text { for } j \neq 0
\end{aligned}
$$


This asymmetric steady state is real and positive (and therefore biologically meaningful) if $n<1+1 /(2 a b)^{2}$. In these conditions, it is always stable. On the other hand, the symmetrical steady state is unstable when the asymmetrical steady state exists, except when $n>1 / a b$, in which case they are both stable (see Appendix B for the stability analysis). The initial conditions determine which of the two steady states is reached. See Fig. 3 for a stability diagram. A bifurcation diagram (Fig. 4) shows the solutions for the particular case of two populations $(n=2)$.

To summarise, the lower the product $a b$, the greater the asymmetry between the two populations. In biological terms, $\left(a b=\alpha \theta / \gamma N_{0}\right)$, this means that a high silk threshold $(\alpha)$ and a high degradation rate $(\theta)$ result in a high asymmetry, even for a very fragmented $(n>>1)$ landscape (Fig 3.). On the contrary, high silk production rates $(\gamma)$ and high initial population sizes $\left(N_{0}\right)$ have an inhibiting effect on the asymmetry.

The evolutionary advantage of this heterogeneous distribution is easy to understand for species subject to Allee effects. By definition, the individual fitness $F$ of such species is an increasing function of the number of individuals $N$, at least up to some extent. Clearly, at very high population sizes the cost of competition outweighs the benefits of group living. Nevertheless, the population sizes we consider here (founding populations) are far below that point. Let $N_{1}$ and $N_{2}$ be two connected populations in a closed system. The inclusive fitness $I F$ of an individual can be calculated as the sum of his direct fitness (his own offspring) and his indirect fitness (his conspecifics' offspring multiplied by their relatedness coefficient $r$ ). Eq. 6 gives the inclusive fitness 
of an individual $i$ of the first population $I F_{i 1}$ and the inclusive fitness for that same individual if he were to move to the second population $I F_{i 2}$.

$$
\begin{aligned}
& I F_{i 1}=F\left(N_{1}\right)\left(1+r\left(N_{1}-1\right)\right)+r F\left(N_{2}\right) N_{2} \\
& I F_{i 2}=r F\left(N_{1}\right)\left(N_{1}-1\right)+F\left(N_{2}\right)\left(1+r N_{2}\right)
\end{aligned}
$$

The fitness difference $\triangle I F$ for the movement from the first population to the second is expressed as $\triangle I F=I F_{i 2}-I F_{i 1}=F\left(N_{2}\right)-F\left(N_{1}\right)$. This fitness difference is a gain when $N_{2}>N_{1}$ and a loss when $N_{2}<N_{1}$. This means that it is always beneficial in terms of fitness to move to the largest population. Therefore, any asymmetry between the two populations should be amplified to maximize the inclusive fitness of all individuals.

\section{Experimental validation of the model}

In order to test the validity of our model on the social spider Anelosimus eximius, we conducted a field experiment on Anelosimus eximius. Previous experiments on a T-maze (Bernard and Krafft, 2002) show that the silk of conspecifics has a retention effect on these spiders. Here, we test whether this retention effect results in the dynamics we predict. We artificially reproduce the particular case of two interconnected founding populations in the field and compare it with our theoretical predictions. This setup offers the possibility to analyse the coupled effects of flow between populations and of departure from the system.

\section{Experimental methods}

Anelosimus eximius is a highly cooperative theridiid spider found throughout Central and South American forests, occupying edge habitat along open 
byways such as roads or riverbanks. The experiments were carried out in this natural habitat. Spiders were collected from various nests along a transect of about $250 \mathrm{~km}$ on the coast of French Guiana following a previously used procedure (Mailleux et al., 2008; Saffre et al., 1999). Thirteen fork shaped trees were used as the setups for thirteen experiments. Each tree was shaped so as to be as similar as possible on each side, by removing branches, then adjusting branch lengths and trimming the number of leaves on either side (Fig. 5A). The local surroundings (a radius of $2 \mathrm{~m}$ ) of each tree were cleared of vegetation to minimize immediate emigration of the spiders after release. At $\mathrm{t}=0$, we placed plastic cups ( $10 \mathrm{~cm}$ deep, $5 \mathrm{~cm}$ wide) containing 50 spiders on each of the two branches. After $t_{1}=24 \mathrm{hrs}$ and $t_{2}=48 \mathrm{hrs}$, the number of spiders on each branch was counted.

\section{Individual Based Model}

It is not convenient to compare experimental results with the solutions of ordinary differential equations (ODE), because the latter only give the mean field results or more precisely the most likely results. Therefore, we formulated an individual based model (IBM), which can be thought of as a stochastic version of our deterministic ODE model. The algorithm for the IBM simulations is described in Fig. 5B. In the IBM, we included the probability $P_{a}$ of spinning an amount $\gamma / P_{a}$ of silk. This allowed us to incorporate the fact that spiders do not spin all the time. It is not really a difference with the ODE model, in the sense that on average, each spider spins $\gamma$ silk per time unit. Therefore, the mean of the results of the IBM simulations match the ODE numerical resolutions (see an example in Fig. 6). 
Results

After 24 hours, the distribution of the spiders between the two cups was already noticeably asymmetric (Fig. 7). We performed binomial tests to show that the distribution of the spiders between the two sides was different from the expected distribution if they had chosen at random, independently from each other, with an equal probability of going to either side (binomial distribution). All experiments except one clearly differed from a binomial distribution ( $\mathrm{p}$-values always lower than 0.0005). The selection of one of the branches did not result from a bias in the setup, because the number of times the left and the right branch were selected was not statistically different from a binomial choice of probability 0.5 (P-value=0.1334). From then onwards, the populations on each side remained stable: a linear regression $\left(R^{2}=\right.$ $0,9249)$ between the populations at 24 hours and 48 hours $\left(P_{48}=s \cdot P_{24}+y_{0}\right)$ shows that the slope is not different from $1(s=1.046(0.9201,1.171))$ and that the $y$-intercept is not different from zero $\left(y_{0}=-0.3966(-5.918,5.125)\right)$.

We ran the IBM simulations, conducting a systematic parameter search (see Appendix C) and found that the parameter set in table 1 provides the best correspondence between the experiments and the simulations (Fig. 7). Although the model does not reproduce the great variability of the experimental results, we found that, on average, the experimental and theoretical results were very close (Table 2 ).

\section{Markers versus conspecifics}

It is interesting at this point to assess the extent to which the patterns we observe in our model are caused by the intervention of a marker. In 
other words, could direct evaluation of the number of individuals produce the same results? In an alternative model where markers do not intervene, the probability to leave decreases with the number of individuals instead of the quantity of silk, according to the same function $f(X)=1 /\left(1+\left(X_{i} / a^{\prime}\right)^{\epsilon}\right)$, where $a^{\prime}=\alpha / N_{0}$. This function is used in other models of conspecific retention (Amé et al., 2004; Jeanson and Deneubourg, 2007).

Let us first look at the case of $n$ interconnected populations in a closed system (there is no departure from the system). The population on the $i^{\text {th }}$ patch is described by Eq. 7 .

$$
d X_{i} / d \tau=-X_{i} f\left(X_{i}\right)+1 /(n-1) \sum_{j \neq i} X_{j} f\left(X_{j}\right)
$$

All that is said about the silk model in $n$ interconnected sites is true of this model too, at least qualitatively. For $\epsilon>1$, there are asymmetric steady states with one population greater than all the others. The values and the stability of the steady states have the same form as the ones of our marker model (see Fig.3 and Fig.4), except for a parameter ( $a^{\prime}$ instead of $a b$ ).

However, this similarity between the two models ceases to be true in an open system that allows exits. Indeed, the transfer of information through markers can provoke qualitative changes in the behaviour of the system. If we look at the effect of departures only (the case of one population), the system is described by Eq. 8 .

$$
d X / d \tau=-X /\left(1+\left(X / a^{\prime}\right)^{\epsilon}\right)
$$

Like the marker model, the alternative model has only one stable steady state $\left(X_{s}=0\right)$. However, in this case there is no asymptotic steady state, 
regardless of the exponent $\epsilon$. We can see this by looking at the evolution of the population $X$ as a function of time. Integration of Eq. 8 gives:

$$
\ln X / X_{0}+\left(X^{\epsilon-1}-X_{0}^{\epsilon-1}\right) / \epsilon a^{\prime}=-\tau
$$

It appears clearly that when time $\tau$ tends to infinity, $X$ tends to zero. Therefore we can conclude that in the alternative model there are no asymptotic steady states. This is an important difference, because it means that the population goes extinct unless the retention effect is secured by a marker that accumulates.

Furthermore, we ran individual-based simulations with the alternative model, searching a wide range of parameters (following the method described in Appendix C), and we could not reproduce our experimental results (see Fig.8). The main feature that we were unable to obtain with the simulations is the stability of the results between 24 and 48 hours. It is impossible for the simulated populations to remain at a constant size for that long, because the retention effect of conspecifics is not sufficiently stable. As conspecifics leave, the probability of leaving increases, and this positive feedback leads the population to extinction. A marker that does not degrade on the other hand creates a much more stable retention effect.

\section{Discussion}

In this study, we examine how retention caused by an indirect indicator of the number of conspecifics - such as the quantity of a marker secreted by conspecifics - affects the dynamics of settlement. The theoretical part of this study provides a few insights into the growth and distribution patterns 
of populations that exhibit this type of positive response to conspecifics.

The experimental part allows us to validate and parameterise the model on Anelosimus eximius.

One key feature of the theoretical results is the importance of the shape of the response function. Indeed, thresholds and asymmetries appear only when the function describing the response to the marker is S-shaped. As Sumpter and Pratt (2009) point out, the non-linearity of individual responses, in particular of sigmoidal responses is key to the speed and accuracy of collective decisions. They call this type of sigmoidal response "quorum response". The difference between our response function and quorum responses, is that in this case the response is not a function of the number of conspecifics, but of a marker that is, in turn, a cumulative function of the number of conspecifics. This difference is crucial because it is precisely this property that is responsible for the appearance of asymptotic steady states, thresholds, and the stability of the populations in an open system. In a closed system, however, the spatial patterns observed (aggregation versus homogeneous distribution) are similar to those obtained with other quorum models (Amé et al., 2004; Jeanson and Deneubourg, 2007), as we show in the previous section.

The agreement between the experiments and the simulations suggests that social spiders respond to silk in a sigmoidal way. This agreement alone is not in itself sufficient to validate the model with certainty. To complete this validation, further experiments would be useful (eg. film the whole experiment to observe the fine kinetics of the collective choice, test different sizes for the total population, or measure individual time of residence in a patch as a function of silk...). Nonetheless, the fact that A.eximius are 
attracted and retained by silk (Bernard and Krafft, 2002), the agreement between our model and the experiments, and the disagreement between tha latter and the alternative model (direct evaluation of conspecifics), altogether make a strong case for our hypothesis.

According to our theoretical predictions on a single population, this sigmoidal response to silk implies that the number of founders has to exceed a critical value for settlement to be successful. This would explain the results of Leborgne et al. (1994), namely that big groups (> 100 spiders) settle successfully where they are released whereas isolated females mostly leave the area after a very short time. It has been shown that isolated females can and do settle alone (Avilés and Trufiño, 1998), although it is quite rare and their survival chances are relatively small (Vollrath, 1982).

There is a substantial amount of evidence that suggests that $A$. eximus, like most cooperative species, is submitted to Allee effects (Avilés and Trufiño, 1998 and the references therein). Strong Allee effects can give rise to thresholds (called Allee thresholds) of colony size under which the population is not viable: if there are not enough individuals in the population, it dies out (Courchamp et al., 2008; Stephens and Sutherland, 1999). The threshold in population size that results from our model is somewhat different from an Allee threshold. In populations below the threshold of our model, the individuals do not die, they just leave. We suspect that both types of threshold exist. The thresholds provoked by silk retention would guarantee that the settling populations are large enough to overcome Allee effects. Silk attraction/retention could therefore have been selected, amongst other reasons, because it ensures that colonies do not settle under a non-viable size. 
We used a binary choice setup to show that spiders tend to adopt an asymmetrical distribution. An almost identical Y-choice setup had been used to show that silk draglines can act as a recruitment factor and lead to group migration (Jeanson et al., 2004a; Saffre et al., 1999). In these experiments, the initial population was placed in the middle of the setup and the spiders were given the choice between the two branches. Eventually they made a collective choice for one of these branches. In our experiments, we start with two populations and observe that the individuals tend to aggregate into one population. The mechanisms at stake are somewhat different but the two phenomena are complementary: while the former experiments show that silk maintains the cohesion of the group, in the latter silk triggers the aggregation and provokes the cohesion of a fragmented group. These two strategies (group migration and settling where the amount of settlers exceeds a threshold) serve the same functional purpose of insuring subsequent growth of the colony. This redundancy confers a high degree of robustness to the system (Hammerstein, 2006): if the group migration fails, silk attraction offers the possibility for the cohesion to be restored.

Although on average our simulations agree with the experiments, they are slightly less scattered than the experimental results. However, this should not discredit the model: the experimental variability could be due to other external parameters that we did not measure or control (micro-climate, particularities of each experimental tree). Nevertheless, we should point out that for the sake of generality, we had to sacrifice some precision in the model. For example, we assumed throughout our study that all the sites were of equal quality. However, in a natural context where the sites may differ in lighting, 
availability of prey, etc... it is likely that the quality of the site influences the decision to leave or to settle and thereby the quantity of silk. In modelling terms, the quality of the site would affect parameter $\beta$ (probability to leave the site when there is no silk), and indirectly also affect the quantity of silk. It would be an interesting perspective to test the distribution and aggregation patterns of the spiders on two sites of different quality experimentally (eg. by controlling the number of leaves on each site). Indeed, the interplay between conspecific attraction and environmental preference can produce a wide range of distribution patterns (Jeanson and Deneubourg, 2007). This question has been studied in other species (Franks et al., 2003; Pratt et al., 2002; Halloy et al., 2007; Jeanson et al.,2004b). Also, we did not take any saturation effect into account, however it would be reasonable to expect settlers to avoid overcrowded areas (Avilés and Trufiño, 1998). Bernard and Krafft (2002) show that hunger decreases attraction for silk. In overcrowded areas, food shortage could provoke a decrease in the retention effect of silk, and hungry individuals would have a higher probability of leaving.

Our model applies to $A$. eximius but also possibly to other social spiders, and even to gregarious territorial spiders, that show different degrees of affinity for silk (Krafft, 1970; Leborgne and Pasquet, 1987; Schuck-Paim and Jimenez Alonso, 2001). Furthermore, silk is spun by many arthropods (see Craig, 1997 for a review). Well-documented examples are caterpillars (Fitzgerald and Costa, 1999), weaver ants (Oecophylla) (Hölldobler and Wilson, 1983), spider mites (Tetranychidae) (Saito, 1986) and of course, spiders (see Vollrath and Selden, 2007 for a review). In many of these species, silk plays a key role in communication, and in favouring cooperative interactions 
(Bernard and Kraft, 2002). There is evidence of affinity for conspecific silk in other spinning arthropods, such as spider mites (Yano, 2008) and caterpillars (Colasurdo and Despland, 2005, Fitzgerald, 1995), therefore it is likely that the predictions we make apply to other species.

In this context, silk can be thought of as an extended phenotype used as a signal. Employing the extended phenotype _ such as a retentive secretion as a signal is common practice in a great number of gregarious species such as cockroaches (Amé et al., 2004) or ants (Depickère et al., 2004; Sempo et al., 2006). Silk carries information about the number of conspecifics in a patch, and it is likely that spiders use that information as a signal. This type of communication offers several advantages. For instance, extended phenotypes are by definition separated in space and in time from the signaller (Schaedelin and Taborsky, 2009). This enables the signaller to allocate energy and time to other purposes whilst the information is conveyed. Furthermore, once produced, the information can be used by any number of receivers for an extended period with no further expenditure of energy.

Colonisation is one of the crucial processes underlying metapopulation dynamics, and is of great importance in the study of invasions and range expansions. In this study we show that affinity for a marker can greatly affect the decision to leave or to settle in a patch. This may have strong implications on colonisation dynamics and in the spatial distribution of populations, specially for species exhibiting fission-fusion patterns (Couzin and Laidre, 2009). Our future work aims at quantifying the influence of retentive markers in an explicitly defined space, where the connexions between different sites are more complex than the ones defined in the present study. So far, 


\section{Aknowledgements}

A.A. is supported by a grant from the FRIA (Fonds pour la Formation à la Recherche dans Industrie et l'Agriculture). A-C.M. is supported by IRSIB (Institut d'encouragement de la Recherche Scientifique et de l'Innovation de Bruxelles). J.L.D. is research associate from the Belgian National Funds for Scientific Research. We also wish to thank D. Lalor, N. Goldman and two anonymous referees for their helpful comments and suggestions.

\section{Appendix A.Integration in the phase plane}

In our model, there are two variables, and there is no simple analytical way of integrating both equations at once. What we propose instead is to look at the behaviour of the system in the phase plane. The phase plane is the plane defined by the variables $X$ and $Z$. We can describe the trajectory of the system from an initial point $\left(X_{0}, Z_{0}\right)$, by integrating the following expression:

$$
d X / d Z=-X /\left((X-b Z)\left(1+(Z / a)^{\epsilon}\right)\right)
$$

This equation can be simplified because we focus on the case where $b=0$ :

$$
d X / d Z=-1 /\left(1+(Z / a)^{\epsilon}\right)
$$

The integral of this equation differs according to $\epsilon$ : 
If $\epsilon=1$,

$$
X=X_{0}-a \ln (1+Z / a)
$$

This curve describes how the population $X$ will vary according to $Z$, starting in the initial point $\left(X=X_{0}, Z=0\right)$. As time advances, the system will move along that curve: the population will logarithmically decrease and the quantity of silk will increase. At the point when the curve crosses the $Z$-axis, the population goes extinct $X=0$. This takes place when $Z=a\left(e^{1 / a}-1\right)$. From then onwards, the system will remain at that point because no individuals will arrive and no silk will be spun.

if $\epsilon=2$, the integral is different:

$$
X=X_{0}-a \tan ^{-1}(a Z)
$$

This curve approaches a horizontal asymptote: as $Z$ tends to infinity, $X$ tends to $X_{A}=X_{0}-a \pi / 2$. This is an asymptotic steady state because it will never be reached, no matter how far we travel along that curve. Therefore as long as $X_{A}$ is positive, the population never goes extinct.

\section{Appendix B. Stability of the symmetric steady state in $n$ intercon- nected populations}

At the symmetric steady state $X_{1}=X_{2} \cdots=X_{n}=1 / n$ and $Z_{1}=$ $Z_{2} \cdots=Z_{n}=1 / n b$. The jacobian matrix can be written as follows: 


$$
\begin{aligned}
& \begin{array}{lllllllll}
\partial X_{1} & \partial X_{2} & \cdots & \partial X_{n} & \partial Z_{1} & \partial Z_{2} & \cdots & \partial Z_{n}
\end{array}
\end{aligned}
$$

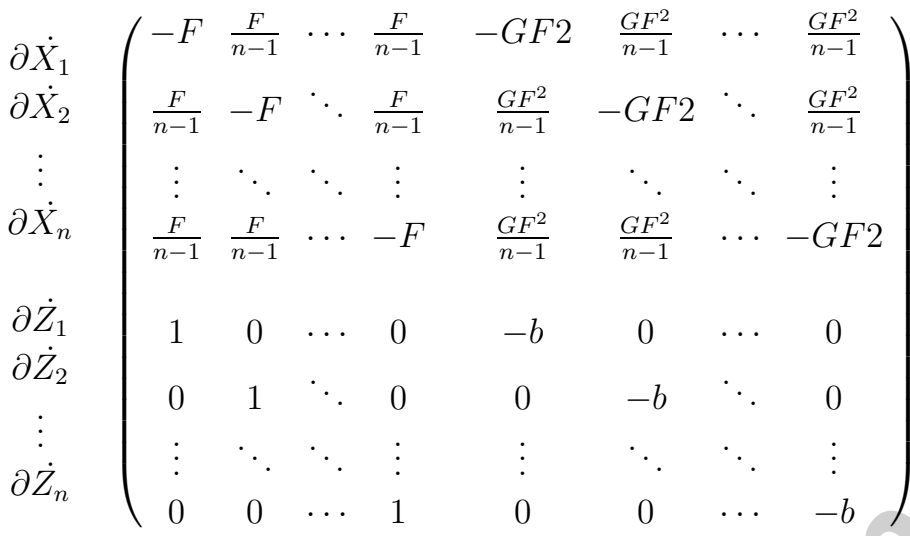

With

$$
F=\frac{1}{1+(1 / a b n)^{2}} \quad \text { and } \quad G=\frac{2}{a^{2} b n^{2}}
$$

We calculate the eigen values associated with the jacobian matrix. The steady state is stable when all of its eigenvalues are negative or zero. There are only four different eigen values of which two $\left(\omega_{3}\right.$ and $\left.\omega_{4}\right)$ are repeated $n / 2-1$ times:

$$
\begin{aligned}
& \omega_{1}=0 \\
& \omega_{3}=\frac{b-n b-n F-\sqrt{(b-n b+n F)^{2}+4 n(n-1) G F^{2}}}{2(n-1)} \\
& \omega_{4}=\frac{b-n b-n F+\sqrt{(b-n b+n F)^{2}+4 n(n-1) G F^{2}}}{2(n-1)}
\end{aligned}
$$

All eigen values are always negative or equal to zero, except $\omega_{4}$. For the symmetric steady state to be stable $\omega_{4}$ cannot be positive. Solving $\omega_{4} \geq 0$ 
leads to

$$
G F \leq b
$$

If we replace $\mathrm{G}$ and $\mathrm{F}$ by their respective expressions, we have

$$
\frac{2}{a^{2} b n^{2}\left(1+(1 / a b n)^{2}\right)} \leq b
$$

which can be reduced to

$$
n \geq \frac{1}{a b}
$$

\section{Appendix C. Systematic parameter search}

Out of the seven parameters of the IBM model, four could be estimated thanks to the following assumptions. We set a time step of one minute as it took approximately one minute for spiders to move from one branch to the other. The asymmetry of the experimental results suggested that $\epsilon>1$, so we took $\epsilon=2$. We assumed that silk did not degrade over the two days of the experiment $(\theta=0)$. We defined one unit of silk as the amount of silk spun by an active spider in one minute, so $\gamma=1$. On average 30 spiders left the setup during the first 48 hours. This allowed us to estimate the probability to exit the $\operatorname{setup} P_{e}=0.01$.

The remaining 3 parameters $\left(\alpha, \beta, P_{a}\right)$ had to be fine tuned. Our knowledge of the system and a preliminary random search helped us define the range that we would test for each of the 3 parameters:

$0 \leq \beta \leq 1$

$0 \leq P_{a} \leq 1$

$1000 \leq \alpha \leq 2000$ 
It is now useful to visualise this parameter space as a three-dimensional grid, each dimension being a parameter and each intersection of the grid being a parameter set. We searched this three-dimensional parameter space by brute force, that is we tested every parameter set (every intersection) and searched for the best correspondence between the experiments and the simulations. Of course near the best correspondence zone, we narrowed the grid in order to get more precision. We chose two criteria to define a good correspondence: (1) a minimal difference between the experimental and simulated averages (total number of spiders and number of spiders in the selected side) for both 24 hours and 48 hours, (2) a maximum number of experiments falling in the $95 \%$ confidence interval of the simulations (see Fig. 6). Expectedly, the optimum for the two criteria coincided in the parameter set we propose.

\section{References}

Amé, J-M., Rivault, C., Deneubourg, J.L., 2004. Cockroach aggregation based on strain odour recognition. Animal Behaviour 68,793-801, doi:10.1016/j.anbehav.2004.01.00

Avilés, L., 1986. Sex-ratio bias and possible group selection in the social spider Anelosimus eximius. American Naturalist 128, 1-12

Avilés, L., Trufiño, P., 1998. Colony Size and Individual Fitness in the Social Spider Anelosimus eximius. American Naturalist 152, 403-418

Bernard, A., and Krafft, B., 2002. L'attraction pour la soie , base de la cohésion du groupe et des comportements collectifs chez les araignées sociales. Comptes Rendus Biologie 325,1-5. 
Christenson, T., 1984. Behaviour of colonial and solitary spiders of the Theridiid species Anelosimus eximius. Animal Behaviour 32,725-734

Colasurdo, N. Despland, E., 2005. Social Cues and Following Behavior in the Forest Tent Caterpillar. Journal of Insect Bhavior 18, 77-87, doi:10.1007/s10905005-9348-6

Courchamp, F., Berec, L., Gascoigne, J., 2008. Allee effects in ecology and conservation. Oxford University Press, New York, NY, USA.

Couzin, I.D., Laidre, M., 2009. Quick Guide: Fission-fusion populations. Current Biology, 19,633-635, doi:10.1016/j.cub.2009.05.034

Craig, C.L., 1997. Evolution of arthropod silks. Annual Review of Entomology 42, 231-267, doi:10.1146/annurev.ento.42.1.231

DeAngelis, D.L., Wilfred M.P., Curtis C.T., 1986. Positive feedback in natural systems. Springer-Verlag,Berlin

Depickère, S., Fresneau,D.,Detrain,C., Deneubourg J.L., 2004. Marking as a decision factor in the choice of a new resting site in Lasius niger. Insectes Sociaux 51, 243246

Doligez, B.,Cadet, C., Danchin,E., Boulinier, T., 2003. When to use public information for breeding habitat selection? The role of environmental predictability and density dependence. Animal Behaviour 66, 973-988, doi:10.1006/anbe.2002.2270 
Fitzgerald, T.D., 1995. The tent-caterpillars. Cornell University Press, Ithaca, NY.

Fitzgerald, T. D., Costa, J.T., 1999. Collective behavior in social caterpillars. pp. 379-400 In: Information Processing in Social Insects. C. Detrain, J. L. Denoubourg, and J. M. Pasteels, eds. Basel: Birkhauser-Verlag.

Fletcher, R.J., 2006. Emergent properties of conspecific attraction in fragmented landscapes. American Naturalist 168, 207-219

Forbes, L. S., Kaiser G.W., 1994. Habitat choice in breeding seabirds, when to cross the information barrier. Oikos 70,377-384

Franks, N.R., Mallon, E.B., Bray, H.E., Hamilton, M.J., Mischler, T.C., 2003. Strategies for choosing between alternatives with different attributes: exemplified by house-hunting ants. Animal Behaviour 65,215-223 doi: 10.1006/anbe.2002.2032

Giraldeau, L.-A., 1997. The ecology of information use. Pages 42-58 in Krebs, J. and N.B. Davies eds. Behavioural ecology, an evolutionary approach. Blackwell, Oxford.

Hammerstein,P. Hagen,E.H., Herz, A.V.M., Herzel, H., 2006. Robustness: A Key to Evolutionary Design. Biological Theory 1,90-93

Halloy J., Sempo, G., Caprari, G., Rivault, C., Asadpour, M., Tâche F., Saïd I., Durier V., Canonge, S., Amé, J-M., Detrain, C., Correll, N., Martinoli, A., Mondada, F., Siegwart, R., Deneubourg, J.L., 2007. Social integration of robots into groups of cockroaches to control self-organized choices. Science 
318,1155-1158 doi: 10.1126/science.1144259

Hölldobler, B., Wilson, E.O., 1983. The evolution of communal nest-weaving in ants. American Scientist 71,490-499.

Jeanson, R., Deneubourg,J.L.,Theraulaz., G., 2004a. Discrete dragline attachment induces aggregation in spiderlings of a solitary species. Animal Behaviour 67,531-537, doi:10.1016/j.anbehav.2003.06.013

Jeanson, R., Deneubourg, J.L., Grimal, A., Theraulaz, G. 2004b. Modulation of individual behavior and collective decision-making during aggregation site selection by the ant Messor barbarus. Behavioural Ecology and sociobiology

Jeanson, R., Deneubourg, J.L., 2007. Conspecific attraction and shelter selection in gregarious insects. American Naturalist 170, 47-58

Krafft B., 1970. Contribution la biologie et l'éthologie d' Agelena consociata Denis (araigne sociale du Gabon) II. Biologia Gabonica 4,307-369.

Leborgne, B., Pasquet, A., 1987. Influence of conspecific silk-structures on the choice of a web-site by the spider Zygielle x-notata (Clerck). Revue Arachnologique 7,85-90.

Leborgne, R., Krafft,B, Pasquet, A., 1994. Experimental study of foundation and development of Anelosimus eximius colonies in the tropical forest of French Guiana. Insectes Sociaux 41,179-189

Mailleux, A-C., Furey, R., Saffre,F., Krafft,B., Deneubourg, J.L., 2008. How 
non-nestmates affect the cohesion of swarming groups in social spiders. Insectes Sociaux 55,355-359

Mihoub, J-B., Le Gouar,P., Sarrazin, F., 2009. Breeding habitat selection behaviours in heterogeneous environments: implications for modelling reintroductions. Oikos 118,663-675

Mueller, K. L., Stamps, J.A., Krishnan,V.V., Willits, N.H., 1997. The effects of conspecific attraction and habitat quality on habitat selection in territorial birds (Troglodytes aedon). American Naturalist 150,650-661

Nentwig, W., 1985. Social spiders catch larger prey: study of Anelosimus eximius (Araneae: Theridiidae). Behavioral Ecology and Sociobiology 17,7985.

Pratt, S.C., Mallon, E.B., Sumpter, D.J.T., Franks, N.R., 2002. Quorum sensing, recruitment, and collective decision-making during colony emigration by the ant Leptothorax albipennis. Behavioral Ecology and Sociobiology $52,117-127$

Ray, C., Gilpin, M., 1991. The effect of conspecific attraction on metapopulation dynamics. Biological Journal of the Linnean Society 42,123-134

Rivault, C., Cloarec, A., Sreng, L., 1998. Cuticular extracts inducing aggregation in the German cockroach, Blattella germanica (L.). Journal of Insect Physiology 44,909918, doi:10.1016/S0022-1910(98)00062-6

Saffre, F., Furey,R., Krafft,B., Deneubourg, J.L., 1999. Collective decisionmaking in social spiders : dragline-mediated amplification process acts as a 
recruitment mechanism. Journal of Theoretical Biology 198,507-517, doi:10.1006/jtbi.1999.0927

Saffre, F., Mailleux, A.-C., Deneubourg, J.L., 2000. Exploratory Recruitment Plasticity in a Social Spider (Anelosimus eximius). Journal of Theoretical Biology 205,37-46, doi:10.1006/jtbi.2000.2042

Saito, Y., 1986. Biparental defense in a spider mite (Acari, Tetranychidae) infesting Sasa bamboo. Behavioural Ecology and Sociobiology 18,377-386.

Schaedelin, F.C., Taborsky, M., 2009. Extended phenotypes as signals. Biological Reviews 84,293-313

Schuck-Paim, C., Jimenez Alonso, W., 2001. Deciding where to settle: conspecific attraction and web site selection in the orb-web spider Nephilengys cruentata. Animal Behaviour 62,1007-1012, doi:10.1006/anbe.2001.1841

Sempo, G., Depickère, S., Detrain, C., 2006. Spatial organization in a dimorphic ant: caste specicity of clustering patterns and area marking. Behavioural Ecology 17,642-650,

Smith, A.T., Peacock, M.M., 1990. Conspecific attraction and the determination of metapopulation colonization rates. Conservation Biology 4, 320-323.

Sumpter, D.J.T., Pratt, S.C., 2009. Quorum responses and consensus decision making. Philosophical Transactions of the Royal Society B 364, 743-753

Stamps, J.A., 1988. Conspecific attraction and aggregation in territorial species. American Naturalist 131,329347. 
Stephens, P.A., Sutherland, W.J., Freckleton, R.P., 1999. What is the Allee effect? Oikos 87,185-90

Venticinque, E. M., Fowler, H. G., Silva, C.A.. 1993. Modes and frequencies of colonization and its relation

Vollrath, F., 1982. Colony foundation in a social spider. Zeitung Tierpsychologie $60,313-324$

Volrath, F., 1986. Environment, reproduction and the sex ration of the social spider Anelosimus eximius (Araneae, Theridiidae). Journal of Arachnology $14,267-281$

Vollrath, F. Selden, P., 2007. The role of behavior in the evolution of spiders, silks, and webs. Annual review of ecology evolution and systematics 38,819846

Wagner, R.H., Danchin, E., 2003. Conspecific copying: a general mechanism of social aggregation. Animal Behaviour 65,405408, doi:10.1006/anbe.2003.2037

Yano, S., 2008. Collective and solitary behaviors of twospotted spider mite (Acari:Tetranychidae) are induced by trail following. Annals of the Entomological Society of America 101,247-252 
Table .1: Variables and parameters.

\begin{tabular}{|c|c|c|c|c|}
\hline Var/Par. & Biological significance & dimension & range of values & fitted values \\
\hline$N$ & number of individuals & $N$ & $0-\infty$ & - \\
\hline$S$ & quantity of silk & $S$ & $0-\infty$ & \\
\hline$N_{0}$ & initial population size & $N$ & $0-\infty$ & \\
\hline$\alpha$ & silk threshold & $S$ & $0-\infty$ & 1846 \\
\hline$\beta$ & maximal departure rate & $t^{-1}$ & $0-10$ & 0.535 \\
\hline$\gamma$ & silk production coefficient & $S N^{-1} t^{-1}$ & $0-\infty$ & 1 \\
\hline$\epsilon$ & sensitivity to threshold & - & $0-\infty$ & 2 \\
\hline$\theta$ & silk degradation coefficient & $t^{-1}$ & $0-1$ & 0 \\
\hline$P_{e}$ & Probability to exit the system & & $0-1$ & 0.01 \\
\hline$P_{a}$ & Probability to be active & - & $0-1$ & 0.05 \\
\hline \multicolumn{5}{|l|}{ Scaled: } \\
\hline$X$ & $N / N_{0}$ & - & {$[0 ; 1]$} & \\
\hline$Z$ & $\beta S / \gamma N_{0}$ & - & {$[0 ; \infty[$} & \\
\hline$a$ & $\alpha \beta / \gamma N_{0}$ & - & {$[0 ; \infty[$} & \\
\hline$b$ & $\theta / \beta$ & - & {$[0 ; \infty[$} & \\
\hline$\tau$ & $\beta t$ & - & {$[0 ; \infty[$} & \\
\hline
\end{tabular}


Table .2: Average results : number of spiders in the largest population $\left(X_{g}\right)$ and total number of spiders left in the tree $\left(X_{T O T}\right)$ after 24 hours and 48 hours. The parameter sets used to compute the simulations in A., B. and C. are the same as in figure 8.

\begin{tabular}{|c|c|c|c|c|}
\hline & \multicolumn{2}{|c|}{$t_{1}=24 h$} & \multicolumn{2}{|c|}{$t_{2}=48 h$} \\
\hline & $X_{g}$ & $X_{T O T}$ & $X_{g}$ & $X_{T O T}$ \\
\hline Experiments (13 replicates) & 57.85 & 68.00 & 61.92 & 70.31 \\
\hline IBM with silk (2000 simulations) & 56.64 & 71.42 & 59.62 & 71.19 \\
\hline \multirow{3}{*}{$\begin{array}{r}\text { IBM without silk (2000 simulations) A. } \\
\text { B. } \\
\text { C. }\end{array}$} & 57.48 & 63.74 & 5.51 & 8.67 \\
\hline & 81.57 & 84.35 & 62.23 & 66.02 \\
\hline & 77.64 & 71.42 & 49.07 & 52.15 \\
\hline
\end{tabular}

Figure .1: Shape of the function describing individual departure rates. When $\epsilon \leq 1$ (A), the shape is hyperbolical. When $\epsilon>1$ (B), the shape is sigmoidal. The maximal departure rate $\beta$ is halved when the quantity of silk reaches $\alpha$.

Figure .2: Timeplots of the fraction of individuals left in the population $(X)$ for different values of $a, \epsilon$ and $b$. For large values of $a$ (B and D), the other parameters $(\epsilon, b)$ do not greatly affect the dynamics. On the contrary, for low values of $a$ (A and $\mathrm{C}$ ), the other parameters have an important influence. When $b=0$ (dashed line), the decrease in population size is the slowest. The population can even stabilise at a given value, provided that $\epsilon>1(\mathrm{C})$. Positive values of $b$ (solid lines) accelerate the extinction process.

Figure .3: Stability diagram in the parameter space defined by $n$ and the product $a b$, for the case of $\epsilon=2$. In the white area, the only stable steady state is the asymmetrical one. In the light grey area, it is the symmetric steady state that is stable. In the dark grey area, both steady states are stable. 
Figure .4: Three-dimensional bifurcation diagram: Values of the steady states $X_{s}$ as a function of the two parameters $a$ and $b$. The black surface represents the unstable steady states, whereas the grayscle surface represents the stable steady states.

Figure .5: Experimental setup (A) and IBM algorithm (B). The dimensions of the trees in $\mathrm{cm}($ mean $\pm \mathrm{STD}): d=54.5 \pm 6.0, D=72.6 \pm 13.3, h=41.1 \pm 7.2, H=47.5 \pm 9.1$ Number of leaves in the right: $15.4 \pm 6.0$ and on the left $d=14.8 \pm 6.0$.

Figure .6: Comparison between the stochastic (solid line) and the deterministic (dashed line) model with equal sets of parameters (IBM: $\alpha=250, \beta=0.5, \gamma=1, \epsilon=2, \theta=0.14$, $P_{e}=0, P_{a}=1$; ODE: $\left.a=2.5, b=0.28, \epsilon=2\right)$. The grey surface represents the standard deviation of the simulations. The steady states are identical, but they are reached faster in the IBM. This is easily explained by the discrete nature of the IBM. While increases in population size in the ODE model are infinitesimal, they are at least of one unit in the IBM, therefore the feedbacks are launched faster.

Figure .7: Experimental and simulation results. The experimental results significantly differ from the binomial distribution with one exception. Our simulation results coincide with the experiments, with the difference that they are slightly less scattered. The contour graph contains two areas: the light grey area contains the $95 \%$ most likely results from 2000 simulations. The dark grey area contains the remaining 5\%. The parameter set used in the simulations is $\alpha=1846, \beta=0.535, \gamma=1, \epsilon=2, \theta=0, P_{e}=0.01, P_{a}=0.05$.

Figure .8: Experimental and simulation (2000 simulations) results for the alternative model. The best fits for 24 hours are rather bad fits for 48 hours and vice versa. If we maximise the goodness of fit for both 24 hours and 48 hours simultaneously, the goodness of fit is poor for both. The parameter sets used are A. $\alpha=18.2, \beta=0.525, \epsilon=2$, $P_{e}=0.0058$; B. $\alpha=14.8, \beta=0.375, \epsilon=2, P_{e}=0.0058$; C. $\alpha=11.4, \beta=0.45$, $\epsilon=2, P_{e}=0.0105$ 
Figure 1

A.

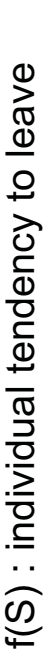

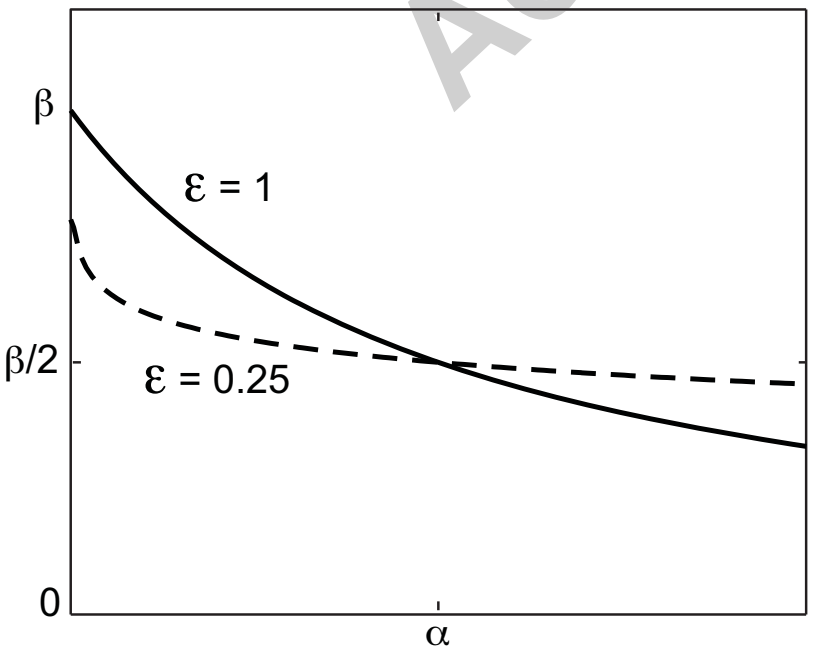

$S$ : quantity of silk
B.

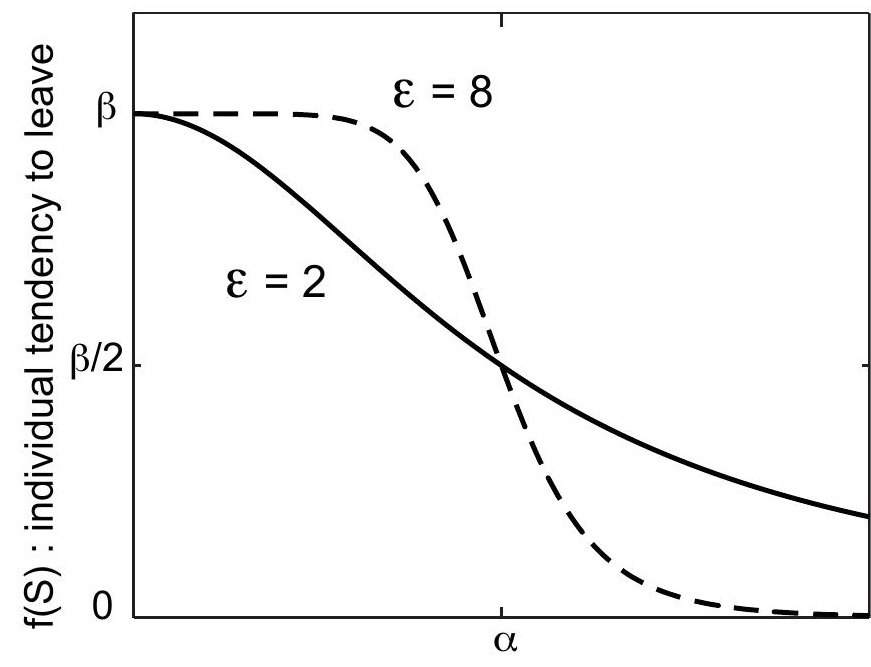

$S$ : quantity of silk 


\section{Figure 2}

$$
a=0.2
$$

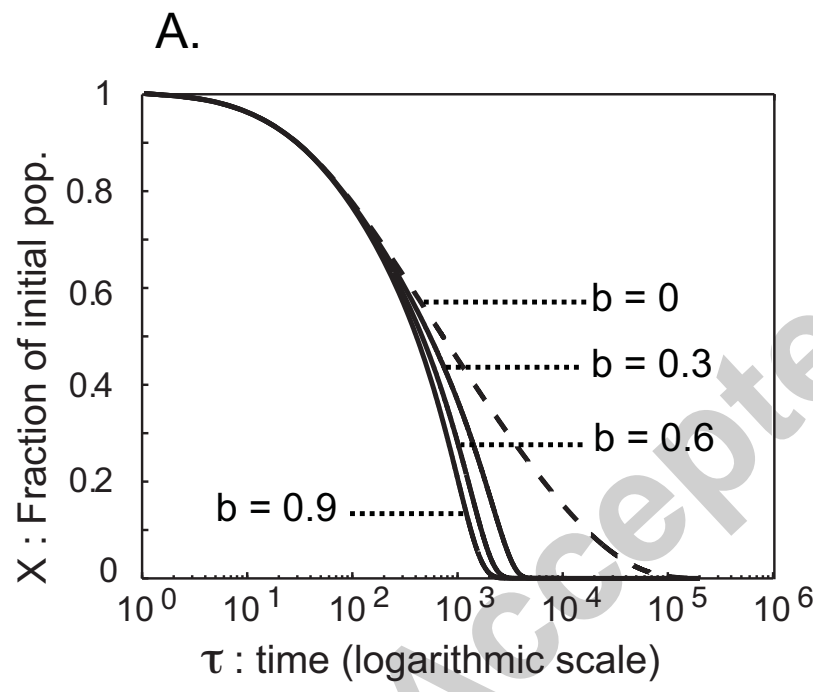

C.

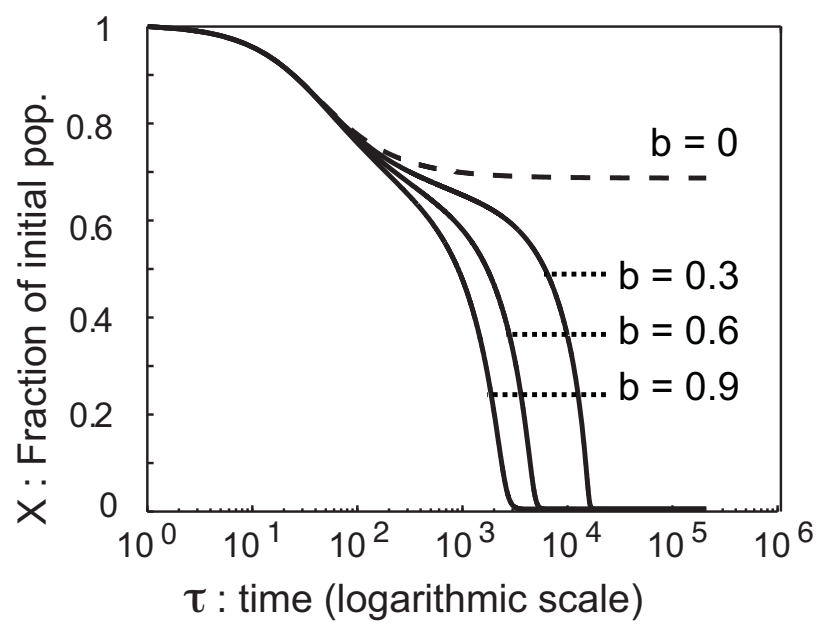

B.

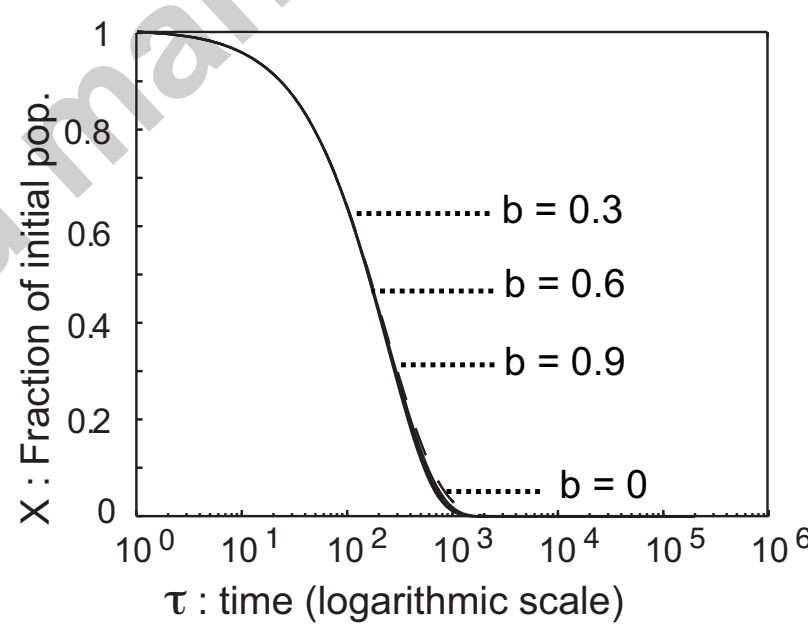

D.

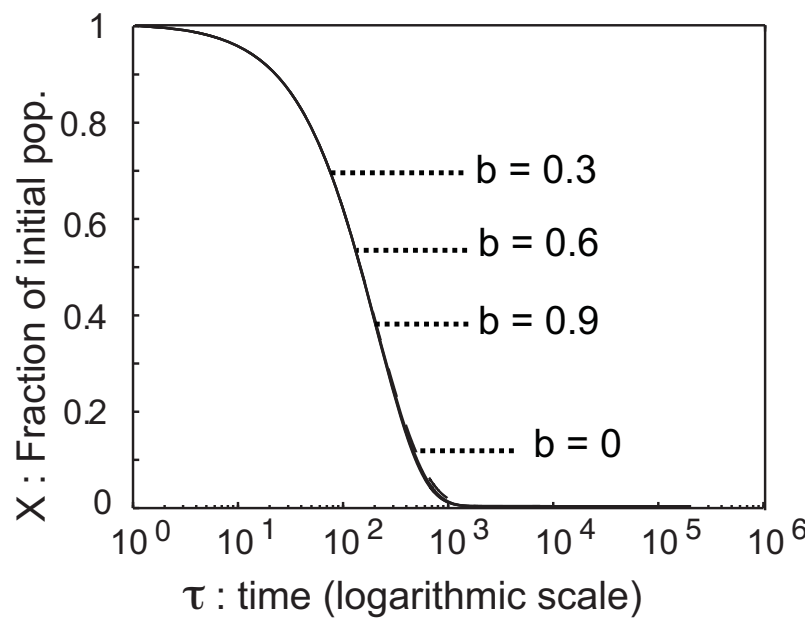


Figure 3

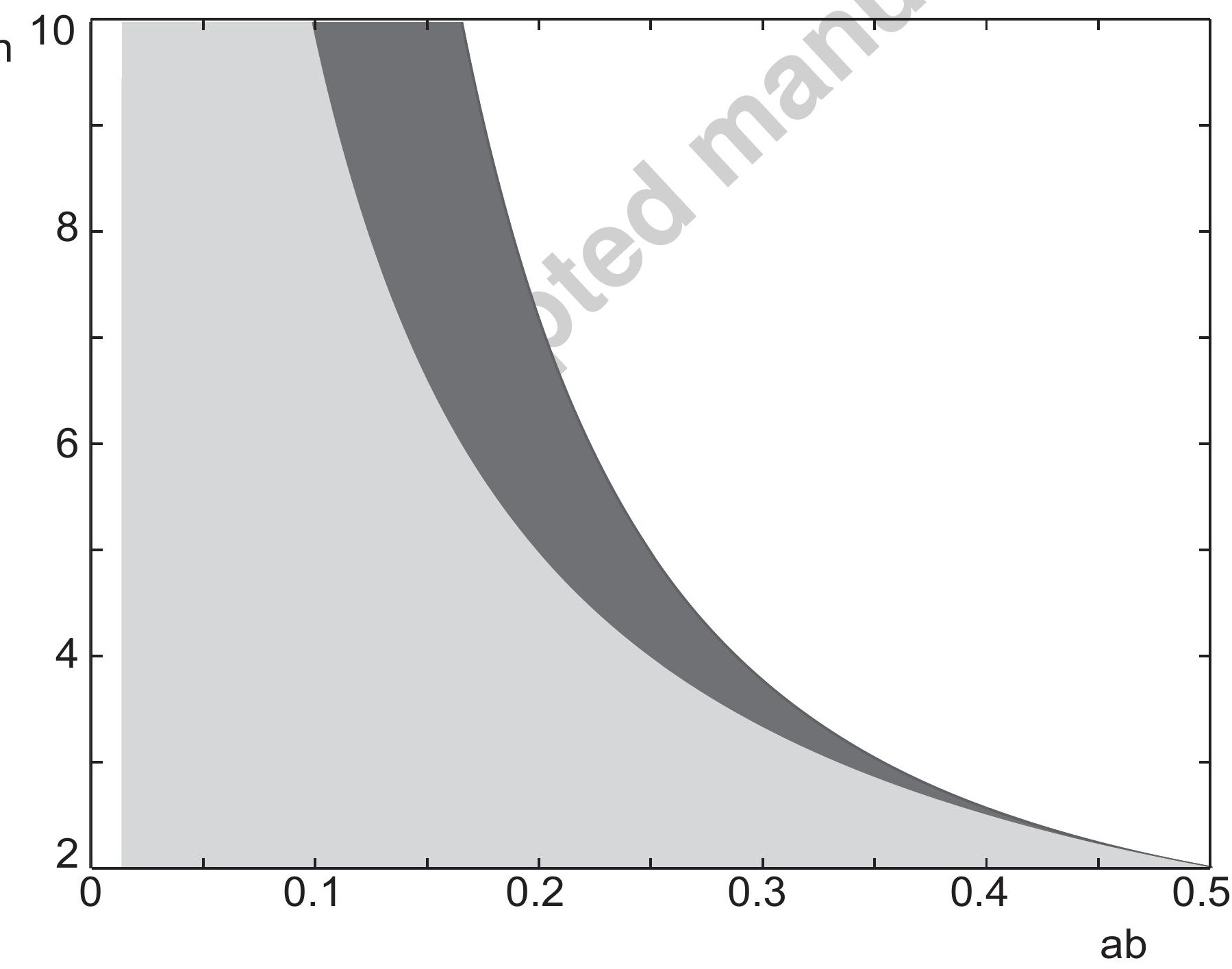




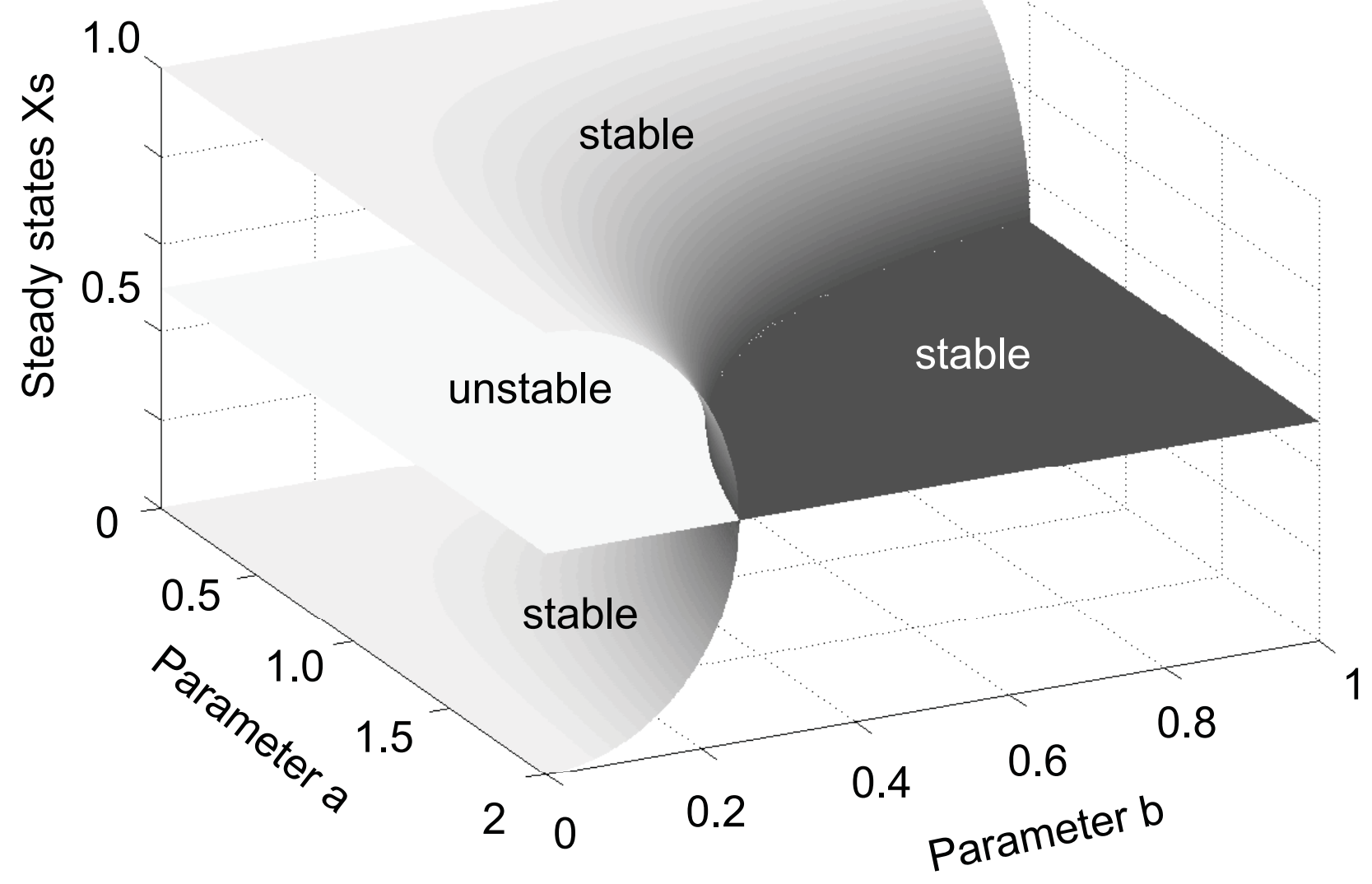


Figure 5

A.

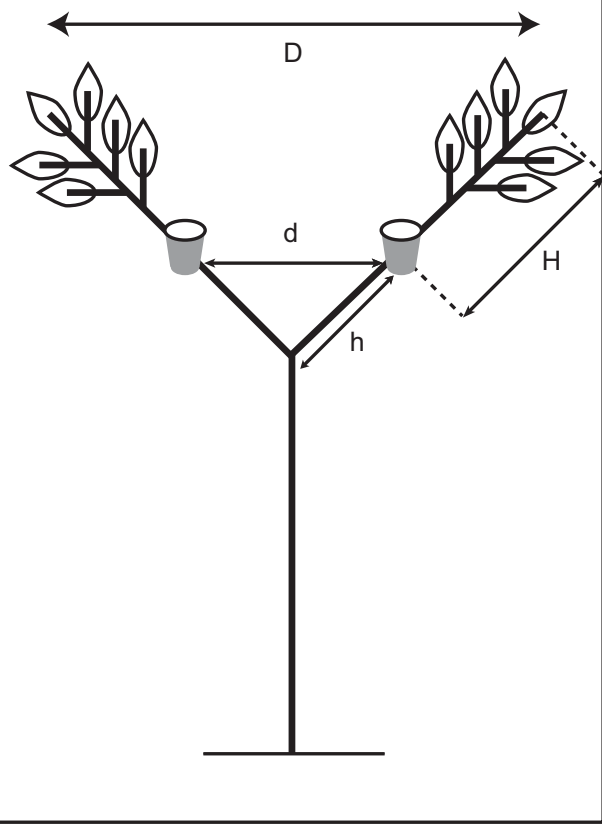

B.

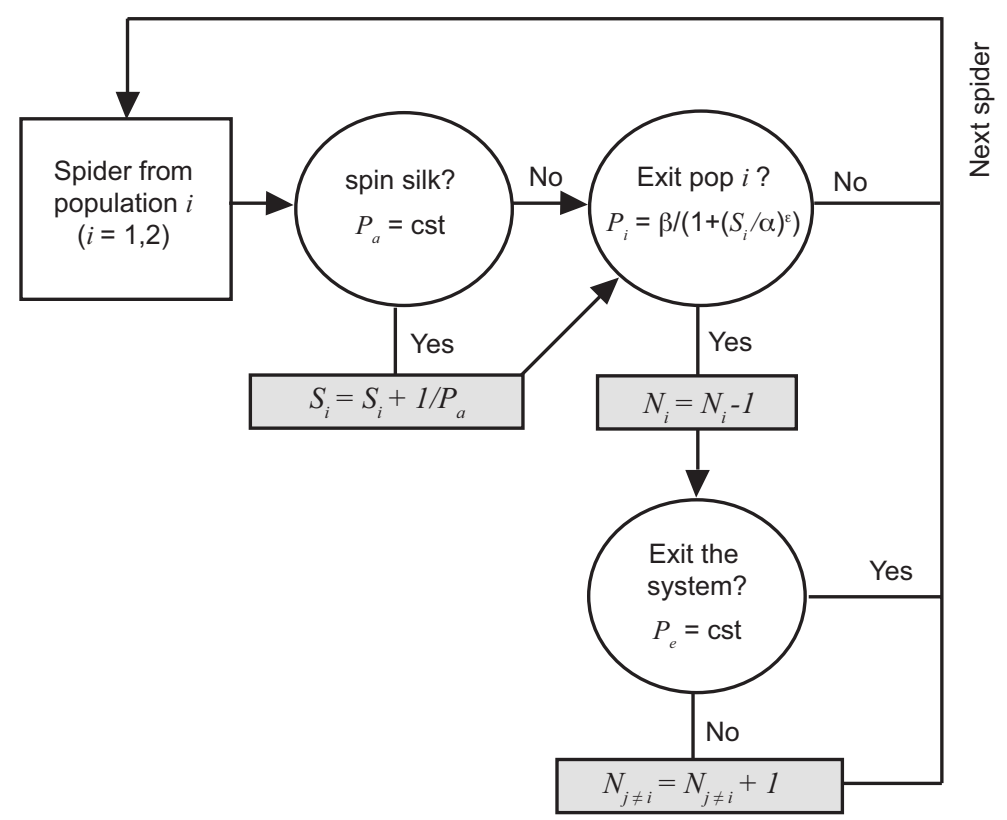


Figure 6

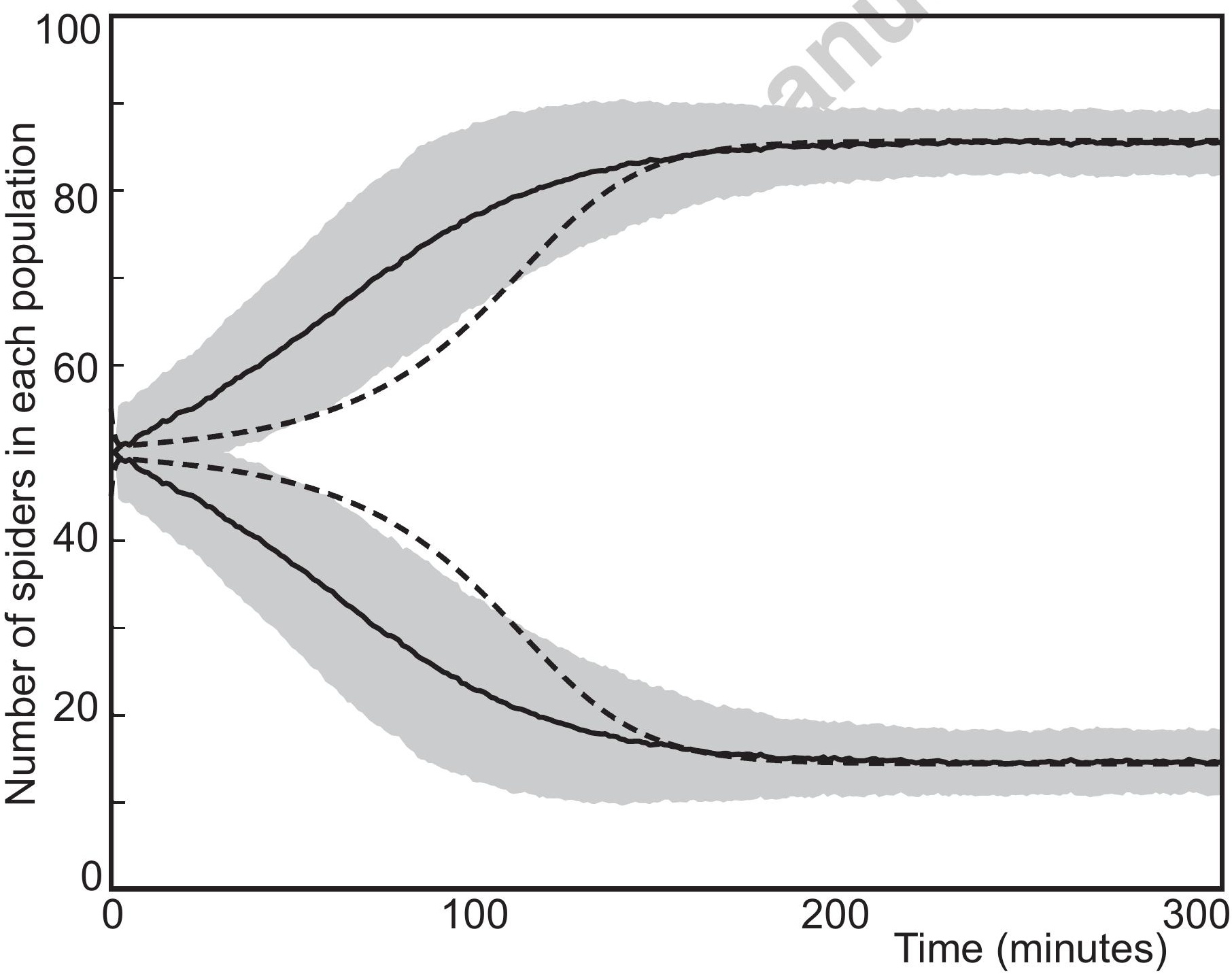




\section{Figure 7}

A. $24 \mathrm{~h}$

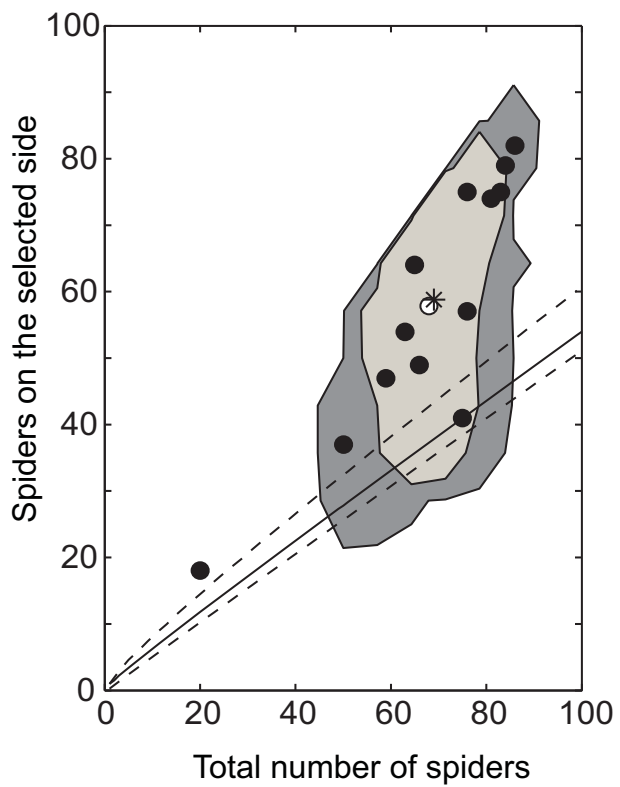

B. $48 \mathrm{~h}$

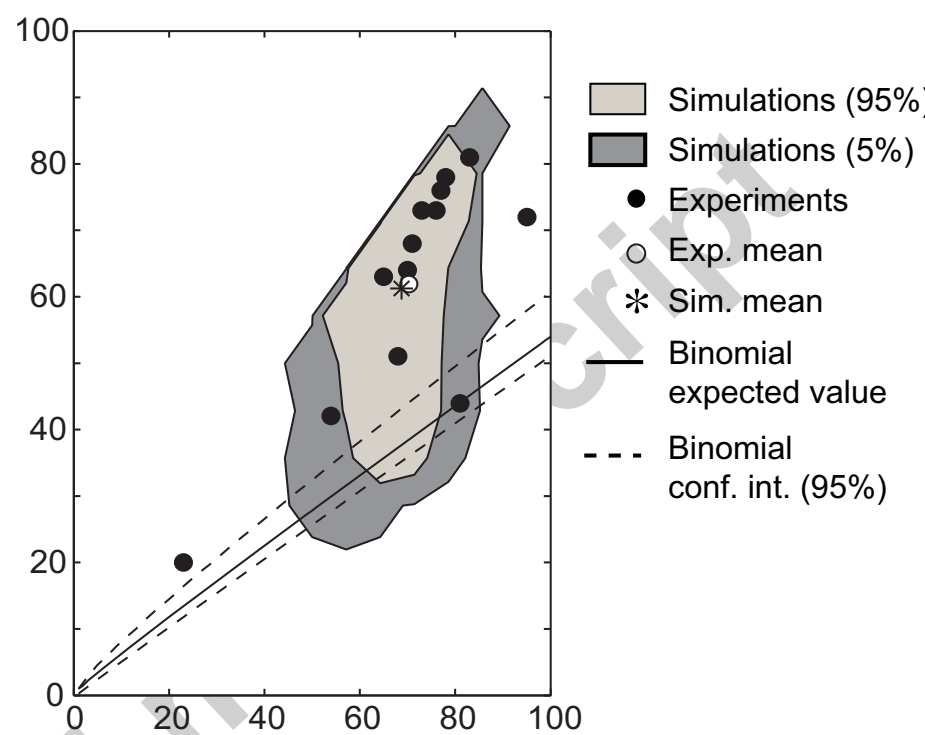


Figure 8

A. Best fit for $24 \mathrm{~h}$
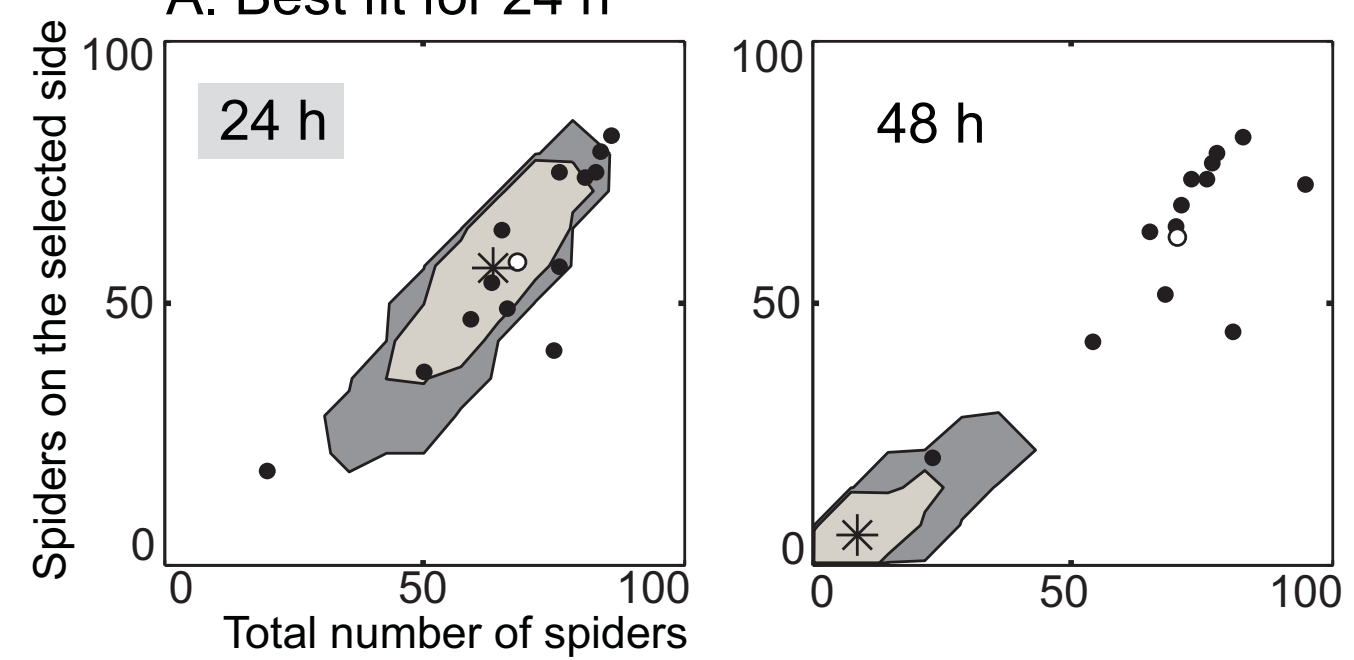

B. Best fit for $48 \mathrm{~h}$
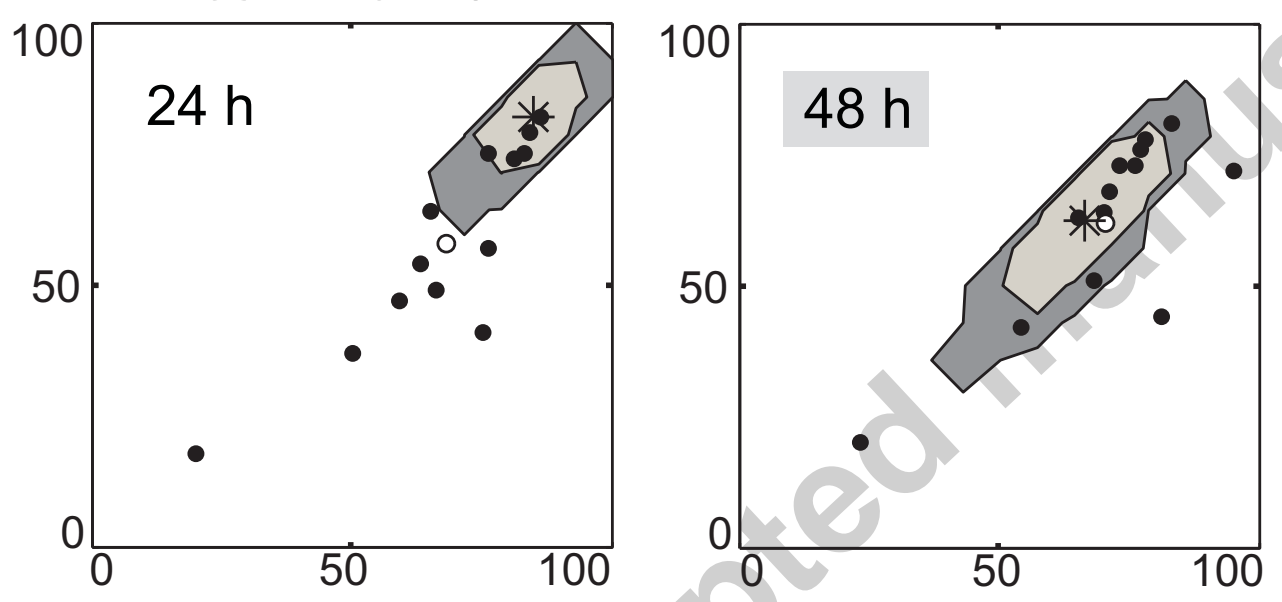

C. Best fit for both $24 \mathrm{~h}$ and $48 \mathrm{~h}$
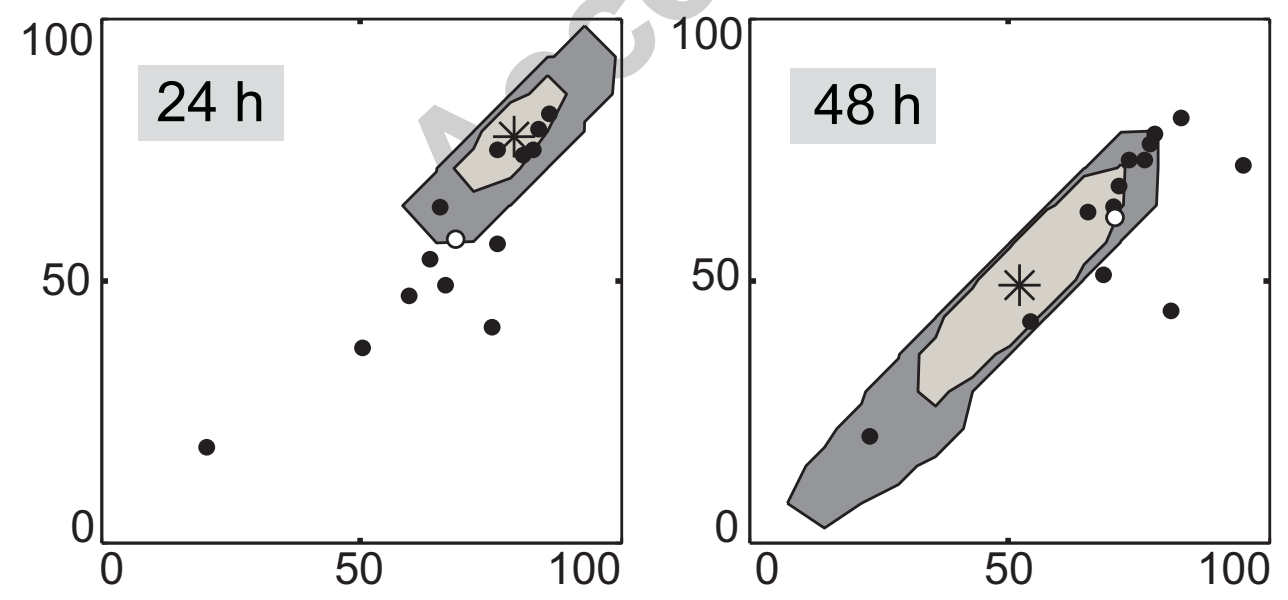

Simulations (95\%) - Experiments

Simulations (5\%) $\bigcirc$ Exp. mean

* Sim. mean 